\title{
February 2014 Phoenix Critical Care Journal Club: Subgroup Analysis
}

\author{
Sun X, loannidis JP, Agoritsas T, Alba AC, Guyatt G. How to use a subgroup \\ analysis: users' guide to the medical literature. JAMA. 2014;311(4):405-11. \\ [CrossRef] [PubMed]
}

One of Dr. Raschke's pet peeves is unplanned subgroup analysis. In the September 2013 Banner Good Samaritan / Phoenix VA Critical Care Journal Club (1) he commented on an article by Hung et al. (2) that used a post hoc subgroup analysis. He felt strongly enough to write to the editor about why post hoc subgroup analysis should not be acceptable as a basis for scientific conclusions and his letter was published this month (3). Therefore, we have been on the lookout for a review article to discuss subgroup analysis and came across this timely publication in JAMA. The authors cite a number of examples and provide 5 criteria to use when assessing the validity of subgroup analyses:

1. Can chance explain the apparent subgroup effect;

2. Is the effect consistent across studies;

3. Was the subgroup hypothesis one of a small number of hypotheses developed a priori with the direction specified;

4. Is there strong preexisting biological support;

5. Is the evidence supporting the effect based on within- or between-study comparisons.

The first 4 criteria are applicable to individual studies or systematic reviews, the last only to systematic reviews of multiple studies. These criteria will help clinicians deciding whether to use subgroup analyses to guide their patient care but we are all in agreement that care must be used when using subgroup analysis to not overestimate an effect.

Geurts M, Macleod MR, Kollmar R, Kremer PH, van der Worp HB. Therapeutic hypothermia and the risk of infection: a systematic review and meta-analysis. Crit Care Med. 2014;42(2):231-42. [CrossRef] [PubMed]

After reviewing Sun's article in JAMA above, we were on the alert for an article doing subgroup analysis and this one was interesting. Briefly, the authors performed a systematic review and meta-analysis of randomized trials to examine the risk of infections in patients treated with hypothermia. Twenty-three studies were identified, which included 2,820 patients, of whom 1,398 $(49.6 \%)$ were randomized to hypothermia. In patients treated with hypothermia, the prevalence of all infections was not increased (rate ratio, 1.21 [95\% Cl, 0.95-1.54]), but there was an increased risk of pneumonia and sepsis (risk ratios, 1.44 [95\% Cl, 1.10-1.90]; 1.80 [95\% Cl, 1.043.10], respectively).

After reviewing Sun's article above, we were all skeptical about concluding that hypothermia caused pneumonia or sepsis especially since the overall rate of infections did not increase. The effect was not consistent between studies, none of the studies other than this meta-analysis hypothesized the association a priori and the preexisting 
biological support appears to be weak. However, we agree with the authors' recommendation that future randomized trials of hypothermia should report infections, pneumonia and sepsis to see if the association holds up.

Schortgen F, Clabault K, Katsahian S, Devaquet J, Mercat A, Deye N, Dellamonica J, Bouadma L, Cook F, Beji O, Brun-Buisson C, Lemaire F, Brochard L. Fever control using external cooling in septic shock: a randomized controlled trial. Am J Respir Crit Care Med. 2012;185(10):1088-95. [CrossRef] [PubMed]

After coming across the article that hypothermia might be associated with pneumonia and sepsis, Dr. Raschke suggested reviewing this article which appeared about two years ago. In this multicenter randomized controlled trial, febrile patients with septic shock requiring vasopressors, mechanical ventilation, and sedation were allocated to external cooling $(n=101)$ to achieve normothermia or no external cooling $(n=99)$. Vasopressors were tapered to maintain the same blood pressure target in the two groups. The primary endpoint was the number of patients with a $50 \%$ decrease in baseline vasopressor dose after 48 hours. from 12 hours of treatment (54 vs. 20\%; $\mathrm{P}<0.001)$ but not at 48 hours (72 vs. $61 \%)$. Shock reversal was significantly more common with cooling and day-14 mortality were significantly lower in the cooling group. Please note that although external cooling was used in both the above meta-analysis on infection and hypothermia and this study, the patient population in this study were septic patients and the goal was to correct fever but not induce hypothermia.

Overall this was a good study that would encourage the use of fever control in septic shock patients. However, aside from this specific group of patients it is unclear if achieving normothermia is beneficial.

van Diepen S, Reynolds HR, Stebbins A, Lopes RD, Džavík V, Ruzyllo W, Geppert A, Widimsky P, Ohman EM, Parrillo JE, Dauerman HL, Baran DA, Hochman JS, Alexander $\mathrm{JH}$. Incidence and outcomes associated with early heart failure pharmacotherapy in patients with ongoing cardiogenic shock. Crit Care Med. 2014;42(2):281-8. [CrossRef] [PubMed]

It seems that $\beta$-blockers are being used for everything these days. Guidelines recommend $\beta$-blockers and renin-angiotensin aldosterone system blockers (ACE inhibitors including angiotensin receptor blockers and aldosterone antagonists) to improve long-term survival in hemodynamically stable myocardial infarction (MI) patients with a reduced left ventricular ejection fraction. This is a subgroup analysis of the TRIUMPH trial which was an international, double-blind, multicenter, randomized, placebo-controlled study that evaluated the effect of tilarginine acetate, a nitric oxide synthase inhibitor, in patients with MI complicated by cardiogenic shock that persisted despite successful infarct artery revascularization. The authors compared 30-day mortality in patients in 66 patients $(27.5 \%)$ had either $\beta$ blocker or ACE inhibitors administered within the first 24 hours after the diagnosis of cardiogenic shock. The observed 30 -day mortality among the treated patients was higher $(27.3 \%$ vs. $16.9 \% ; p=$ $0.035)$. In further subgroup analysis, the mortality was higher in those treated with only 
a $\beta$ blocker (33.3\% vs. $16.9 \%, p=0.017)$ but not among those only treated with ACE inhibitors $(18.2 \%$ vs. $16.9 \%, p=1.000)$.

Even though this was a subgroup analysis, this manuscript supports the concept that $\beta$ blockers in Ml complicated by cardiogenic shock are probably harmful despite guidelines that might be interpreted as encouraging their use.

Adhikari NKJ, Dellinger RP, Lundin S, Payen P, Vallet B, Gerlach H, Park KJ, Mehta S, Slutsky AS, Friedrich JO. Inhaled nitric oxide does not reduce mortality in patients with acute respiratory distress syndrome regardless of severity: systematic review and meta-analysis. Crit Care Med. 2014;42(2):404-12. [CrossRef] [PubMed]

I have always been skeptical that inhaled nitric oxide (NO) does much for the adult respiratory distress syndrome (ARDS) other than transiently improve oxygenation presumably by dilating pulmonary arteries to areas of good ventilation. This metaanalysis included 9 trials ( $n=1,142$ patients) of inhaled NO in ARDS patients. NO did not reduce mortality in patients with severe ARDS $(p=0.93 ; n=329$, six trials) or mildmoderate ARDS ( $p=0.33 ; n=740$, seven trials). The authors tried to look at several subgroups but could find no group that NO appeared to improve survival.

Inhaled NO may have a role in transiently increasing oxygenation in the severely hypoxic patient but these patients appear to be relatively rare. A number of years of ago an editorial was written by Warren Zapol entitled "Nitric oxide in acute respiratory distress syndrome: it works but can we prove it?" (4). It appears the answer is NO. It may be time to bury the concept that inhaled nitric oxide has much of a therapeutic role in ARDS, other than the severely hypoxic patient.

\section{Reade MC, Finfer S. Sedation and delirium in the intensive care unit. $\mathrm{N}$ Engl J} Med. 2014;370(5):444-54. [CrossRef] [PubMed]

Sedation and delirium are "hot" topics in the critical care world. Overall, this is a good review. There are also guidelines on this topic from the Society of Critical Care medicine (5). Both this review article and the guidelines restate the obvious (delirium is associated with higher mortality, EEG should be monitored in patients with seizures, etc.) but it is surprising how little quality data is available. In the guidelines most of the recommendations fall into $B$ and $C$ categories.

Richard A. Robbins, MD

Editor

\section{References}

1. Raschke RA. September 2013 banner good samaritan / phoenix va critical care journal club. Southwest J Pulm Crit Care. 2013;7(4):241-4. [CrossRef] 
2. Hung IF, To KK, Lee CK, Lee KL, Yan WW, Chan K, Chan WM, Ngai CW, Law KI, Chow FL, Liu R, Lai KY, Lau CC, Liu SH, Chan KH, Lin CK, Yuen KY. Hyperimmune IV immunoglobulin treatment: a multicenter double-blind randomized controlled trial for patients with severe 2009 influenza A(H1N1) infection. Chest. 2013;144(2):46473. [CrossRef] [PubMed]

3. Raschke RA. Post hoc subgroup analysis. Chest. 2014;145:435. [CrossRef] [PubMed]

4. Zapol WM. Nitric oxide in acute respiratory distress syndrome: it works but can we prove it? Crit Care Med. 1998;26(1):2-3. [CrossRef] [PubMed]

5. Barr J, Fraser GL, Puntillo K, et al. Clinical practice guidelines for the management of pain, agitation, and delirium in adult patients in the intensive care unit. Crit Care Med 2013;41:263-306. [CrossRef] [PubMed] 